\title{
Role of Optical Coherence Tomography (OCT) in Early Detection of Subclinical Cystoid Macular Edema after Nd-YAG Laser Capsulotomy
}

\author{
Muhammad Adnan ${ }^{1}$, Shela Dareshani ${ }^{2}$, Khowaja Faiz-ur-Rab ${ }^{3}$, Tariq Saleem ${ }^{4}$, Mazhar Ali $^{5}$ \\ ${ }^{1-5}$ Department of Ophthalmology, Unit 1, Dow University of Health Sciences, Karachi
}

\begin{abstract}
Purpose: To determine role of optical coherence tomography (OCT) in early detection of subclinical cystoid macular edema (CME) after Nd-YAG laser capsulotomy in patients with posterior capsular opacification (PCO).

Study Design: Descriptive case-series.

Place and Duration of Study: Department of Ophthalmology Unit 1, Dow University of Health Sciences and Civil Hospital Karachi from 1-July-2015 to 31-Dec-2015.

Methods: A total of 72 eyes with unilateral or bilateral visually significant PCO following uncomplicated cataract surgery with posterior chamber intraocular lens implantation were included in the study. Patients with corneal opacities, glaucoma, retinopathy, maculopathy, optic neuropathy, complicated cataract surgery, previous ocular surgery other than cataract surgery and High refractive errors were excluded from the study. Best-corrected visual acuity (BCVA), Slit lamp examination, posterior segment examination and macular thickness was measured using spectral domain (TOPCON 3D OCT) optical coherence tomography before laser and at 1 week and at 1 month after laser.
\end{abstract}

Results: Mean age was $55.76 \pm 5.28$ with confidence interval of $55.02-56.49$ years. Forty were males and 32 were females. Subclinical cystoid macular edema (CME) was found in $10(14 \%)$ patients. Out of the patients who had CME, 3 were in age group of 40-55 years and seven were in age group of 56-70 years. $P$ value was found to be significant i.e. $(P=0.039)$.

Conclusion: Optical coherence tomography OCT is a non invasive and useful tool for early detection and management of subclinical cystoid macular edema after Nd-YAG laser capsulotomy in patients having posterior capsular opacification (PCO).

Key Words: Cystoid Macular Edema, Nd-YAG laser, Posterior Capsular Opacification. Optical Coherence Tomography (OCT).

How to Cite this Article: Adnan M, Dareshani S, Rab F, Saleem T, Ali M. Role of Optical Coherence Tomography (OCT) in Early Detection of Subclinical Cystoid Macular Edema after Nd-YAG Laser Capsulotomy. Pak J Ophthalmol. 2021, 37 (1): 34-37.

Doi: https://doi.org/10.36351/pjo.v37i1.1143

Correspondence: Muhammad Adnan

Department of Ophthalmology

Unit 1, Dow University of Health Sciences

Karachi

Email: adnanshaikh1986@hotmail.com

Received: October 8, 2020

Accepted: November 15, 2020

\section{INTRODUCTION}

Cystoid macular edema (CME) is one of the main causes of poor visual outcome following uncomplicated cataract surgery. The incidence of postoperative CME following cataract surgery is 0.6$2.6 \%$ which is diagnosed by the presence of macular cysts and/or decreased visual acuity. ${ }^{1}$ CME affects both genders equally and has no racial predominance. 
It is caused by various groups of diseases including ocular inflammatory diseases (uveitis, scleritis,), retinal vascular diseases (retinal vein occlusion, diabetic retinopathy) and retinal dystrophies (retinitis pigmentosa). It can also occur post-operatively (after cataract surgery, YAG laser capsulotomy, laser photocoagulation) and after certain drugs administration (topical 2\% adrenaline, topical latanoprost). ${ }^{2,3}$

Nd:YAG laser capsulotomy is an out-patientdepartment procedure with few complications which can occur like lens pitting, IOP rise, retinal detachment and cystoid macular edema. ${ }^{4}$ The exact cause of CME is not known and its pathogenesis is thought to be due to multiple factors. Macular edema may be due to damage to the blood aqueous barrier which is caused by inflammatory mediators released due to movement and damage of the vitreous gel. ${ }^{5}$ As a result, transudates accumulate in the outer plexiform layer and inner nuclear layers resulting in cystoid spaces at macula called CME. ${ }^{5-6}$ When foveal edema and retinal thickening is more than $300 \mathrm{um}$ it is clinically visualized by slit lamp bio-microscope by using green light to delineate the cystoid spaces. Retinal imaging like Fundus Fluorescein Angiography (FFA) and Optical Coherence Tomography (OCT) are used to detect subclinical macular edema less than $300 \mathrm{um}^{7}$ Different incidences have been reported by different studies from $0.85 \%$ to $9.6 \%$ of cystoid macular edema after Nd:YAG laser capsulotomy. ${ }^{8,9}$ For monitoring macular thickness OCT is a useful tool in patients undergoing Nd:YAG laser capsulotomy. ${ }^{10,11}$

Now-a-days Nd:Yag laser capsulotomy is a frequently performed procedure in OPD for PCO patients. Cystoid macular edema is the most common cause of decreased vision in patients following capsulotomy. Once CME becomes chronic, there is permanent damage to the macular architecture that results in loss of quality of vision. The rationale of our study was to make an early diagnosis of CME by doing early OCT, and treat CME early to prevent permanent damage to macula.

The main objective of this study was to determine the role of optical coherence tomography (OCT) in early detection of cystoids macular edema (CME) after $\mathrm{Nd}-\mathrm{YAG}$ laser capsulotomy in patients with posterior capsular opacification (PCO).

\section{METHODS}

It was a descriptive case series study done at the department of Ophthalmology Unit 1 Dow University of Health Sciences and Civil Hospital Karachi. It was carried out from July 2015 to December 2015. Sample size was calculated by using WHO sample size calculator by taking frequency of CME i.e. $\mathrm{P}=(10 \%)$, margin of error $(d)=6 \%$, Confidence Interval $=95 \%$. The estimated sample size was 72 eyes. Nonprobability consecutive sampling technique was used. Inclusion criteria comprised of patients with unilateral or bilateral visually significant PCO following uncomplicated cataract surgery with posterior chamber intraocular lens implantation. All those PCO cases in which there was reasonable fundal view on non-contact lens fundoscopy. It was made sure that the time-period after cataract surgery was not less than 6 months. Age range was between 40 and 70 years. Either sex were included. Patients with corneal opacities, glaucoma, retinopathy, maculopathy, optic neuropathy, diabetes mellitus, complicated cataract surgery, previous ocular surgery other than cataract surgery and patients with high refractive errors greater than -6.0 or +6.0 diopters were excluded from the study. Consent was taken from the recruited patients. All patients had a complete ocular examination before and one month after Nd:YAG laser capsulotomy. Best-corrected visual acuity (BCVA), Slit lamp examination, posterior segment examination and macular thickness was measured using spectral domain (TOPCON 3D OCT) optical coherence tomography before laser and at 1 week and at 1 month after laser. Tropicamide $1 \%$ was administered for dilation of pupil before the procedure. After capsulotomy, prednisolone acetate $1 \%$ four times daily for 5 days was prescribed. Data was analyzed using SPSS version 20. Mean and standard deviations were calculated for age and visual acuity (VA). Frequencies and percentages were calculated for gender, side of eyes and outcome variable that is CME (yes/no). Effect modifier were controlled through age, gender and side of eyes to see the effect of these on outcome variable. Chi-square test was used with $\mathrm{P} \leq$ 0.05 taken as significant.

\section{RESULTS}

In this study 72 eyes of 72 patients were included to assess the cystoid macular edema (CME), among the patients who underwent Nd-YAG laser capsulotomy for Posterior Capsular Opacification (PCO). Mean age was $58.23 \pm 8.46$ years with C.I $(56.24-60.21)$ years. 
Out of 72 patients 12 had visual acuity between $6 / 6-$ $6 / 9,29$ had $6 / 12-6 / 18$ and 31 had $6 / 24-6 / 60$ as shown in Table 1.

Table 1:

\begin{tabular}{ccc}
\hline Visual Acuity & Frequency & Percentage (\%) \\
\hline $6 / 6-6 / 9$ & 12 & 17 \\
$6 / 12-6 / 18$ & 29 & 40 \\
$6 / 24-6 / 60$ & 31 & 43 \\
\hline
\end{tabular}

Out of 72 patients $40(56 \%)$ were male and 32 (44\%) were females. Thirty-five (49\%) had right and $37(51 \%)$ had left eye affected. eyes Cystoid macular edema (CME) was seen in $10(14 \%)$ while $62(86 \%)$ eyes were normal. Out of 10 patients who had CME, three were in age group of $40-55$ years and seven were in age group of $56-70$ years. $\mathrm{P}$ value was found to be significant i.e. $(\mathrm{P}=0.039)$. Regarding gender $\mathrm{p}$ value was not significant i.e. $(\mathrm{P}=0.519)$. Status of visual acuity is shown in table 1 .

\section{DISCUSSION}

Most common late complication after cataract surgery is posterior capsular opacification (PCO). Definitive treatment option for PCO patients is Nd-YAG laser capsulotomy. Parajuli et al in his study found gross increase in macular thickness after Nd:YAG laser capsulotomy which did not need any treatment. ${ }^{12}$ Other studies have reported Retinal detachment and macular edema as complications after Nd-YAG laser capsulotomy. ${ }^{13}$ The possible mechanism could be liquefaction of the vitreous and disruption of the anterior hyaloid face. Ari et al found gross increase in macular thickness after Nd-YAG capsulotomy which was significantly high in patients who received higher energy. ${ }^{14}$ Karahan et al found significant central macular thickness after Nd:YAG capsulotomy after 7 days which reduced to pre YAG levels after one month irrespective of the capsulotomy size. ${ }^{15}$ Raza reported CME in 3\% of 550 patients treated with Nd:YAG laser capsulotomy for pseudophakic and aphakic PCO. ${ }^{16}$ In our study 10 patients developed subclinical CME at $1^{\text {st }}$ week follow-up which was detected on OCT and after 1 to 3 months, it improved significantly.

There are other studies as well which have shown no statistically significant changes in retinal, and optical nerve fiber layer thicknesses after YAG capsulotomy. ${ }^{17,18}$ Although slight thickness changes in these structures were observed, particularly during the first days. Another author found that foveal thickness did not change in the first year after Nd:YAG laser capsulotomy, as determined by OCT. ${ }^{19}$ Increase in Sub-foveal choroidal thickness after YAG capsulotomy was also reported in a Japanese study. ${ }^{20}$

Limitations of this study include not considering the visual status of the patient with regard to macular thickening. Laser shots and power was also not taken into account.

\section{CONCLUSION}

Optical coherence tomography OCT is a non invasive and useful tool for early detection and management of cystoid macular edema after Nd: Yag Laser Capsulotomy in patients having Posterior Capsular Opacification (PCO).

\section{Ethical Approval}

The study was approved by the Institutional review board/ Ethical review board. (CPCP/REU/OPL-2012183-1473)

\section{Conflict of Interest}

Authors declared no conflict of interest

\section{REFERENCES}

1. Apple DJ, Solomon KD, Tetz MR. Posterior capsule opacification. Surv Ophthalmol. 1992; 37 (2): 73-116.

2. Bertelmann E, Kojetinsky C. Posterior capsule opacification and anterior capsule opacification. Curr Opin Ophthalmol. 2001; 12 (1): 35-40.

3. Schaumberg DA, Dana MR, Christen WG, Glynn RJ. A systematic overview of the incidence of posterior capsule opacification. Ophthalmology, 1998; 105 (7): 1213-1221.

4. Novotny GE, Pau H. Myofibroblast-like cells in human anterior capsular cataract. Virchows Arch A Pathol Anat Histopathol. 1984; 404 (4): 393-401.

5. McDonnell PJ, Zarbin MA, Green WR. Posterior capsule opacification in pseudophakic eyes. Ophthalmology, 1983; 90 (12): 1548-1553.

6. Cobo LM, Ohsawa E, Chandler D. Pathogenesis of capsular opacification after extracapsular cataract extraction: An animal model. Ophthalmology, 1984; 91 (7): 857-863.

7. Wormstone IM. Posterior capsule opacification: a cell biological perspective. Exp Eye Res. 2002; 74 (3): 337347. 
8. Meacock WR, Spalton DJ, Stanford MR. Role of cytokines in the pathogenesis of posterior capsule opacification. Br J Ophthalmol. 2000; 84 (3): 332-336.

9. Saika S, Ohmi S, Kanagawa R. Lens epithelial cell outgrowth and matrix formation on intraocular lenses in rabbit eyes. J Cataract Refract Surg 1996; 22 (Suppl. 1): $835-840$.

10. Lee EH, Seomun Y, Hwang KH. Over expression of the transforming growth factor-beta-inducible gene betaig-h3 in anterior polar cataracts. Invest Ophthalmol Vis Sci. 2000; 41 (7): 1840-1845.

11. Lee EH, Joo CK. Role of transforming growth factorbeta in transdifferentiation and fibrosis of lens epithelial cells. Invest Ophthalmol Vis Sci. 1999; 40 (9): 20252032.

12. Parajuli A, Joshi P, Subedi P, Pradhan C. Effect of $\mathrm{Nd}$ :YAG laser posterior capsulotomy on intraocular pressure, refraction, anterior chamber depth, and macular thickness. Clin Ophthalmol. 2019; 13: 945952.

13. Wesolosky JD, Tennant M, Rudnisky CJ. Rate of retinal tear and detachment after neodymium: YAG capsulotomy. J Cataract Refract Surg. 2017; 43 (7): 923-928.

14. Ari S, Cingü AK, Sahin A, Çinar Y, Çaça I. The effects of Nd: YAG laser posterior capsulotomy on macular thickness, intraocular pressure, and visual acuity. Ophthalmic Surg Lasers Imaging Retina. 2012; 43 (5): 395-400.

15. Karahan E, Tuncer I, Zengin MO. The effect of ND:YAG laser posterior capsulotomy size on refraction, intraocular pressure, and macular thickness. J Ophthalmol. 2014; 2014: 846385.

16. Raza A. Complications after Nd: YAG posterior capsulotomy. J Rawalpindi Med Coll. 2007; 11: 27-29.

17. İsa $\mathbf{Y}$, Emine $\mathbf{P}$, Yudum $\mathbf{Y}$, Sümeyra $\mathbf{Y}$, Nurettin $\mathbf{B}$, Melek DY, et al. Optic coherence tomography measurement of choroidal and retinal thicknesses after uncomplicated YAG laser capsulotomy. Arq. Bras. Oftalmol. 2015; 78 (6): 344-347.
18. Wróblewska-Czajka E, Wylegała E, Tarnawska D, Nowińska A, Dobrowolski D. Assessment of retinal thickness obtain by optical coherence tomography after Nd: YAG capsulotomy. Klin Oczna. 2012; 114 (3): 194-197.

19. Altiparmak UE, Ersoz I, Hazirolan D, Koklu B, Kasim R, Duman S. The impact of Nd:YAG capsulotomy on foveal thickness measurement by optical coherence tomography. Ophthalmic Surg Lasers Imaging, 2010; 41 (1): 67-71.

20. Fujiwara A, Shiragami C, Shirakata Y, Manabe S, Izumibata S, Shiraga F. Enhanced depth imaging spectral-domain optical coherence tomography of subfoveal choroidal thickness in normal Japanese eyes. Japan J Ophthalmol. 2012; 56 (3): 230-235.

\section{Authors' Designation and Contribution}

Muhammad Adnan; Medical Officer: Concepts, Design, Literature search, Data acquisition, Data analysis, Manuscript preparation, Manuscript editing.

Shela Dareshani; Associate Professor: Design, Statistical analysis, Manuscript preparation, Manuscript review.

Khowaja Faiz-ur-Rab; Assistant Professor: Statistical analysis, Manuscript preparation, Manuscript editing.

Tariq Saleem; Assistant Professor: Literature search, Data acquisition, Data analysis.

Mazhar Ali; Consultant Ophthalmologist: Literature search, Data analysis, Manuscript review. 